\title{
The invasive alien freshwater flatworm Girardia tigrina (Girard, 1850) (Platyhelminthes, Tricladida) in Western Europe: new insights into its morphology, karyology and reproductive biology
}

\author{
Giacinta Angela Stocchino \\ Dipartimento di Medicina Veterinaria, Università di Sassari, Via Vienna 2, 07100, \\ Sassari, Italy \\ stocchin@uniss.it
}

Ronald Sluys

Naturalis Biodiversity Center, P.O. Box 9517, 2300, RA Leiden, The Netherlands

\section{Abdel Halim Harrath}

Department of Zoology, College of Science, King Saud University, P.O. Box 2455, Riyadh 11451, Saudi Arabia

\section{Lamjed Mansour}

Department of Zoology, College of Science, King Saud University, P.O. Box 2455, Riyadh 11451, Saudi Arabia

\author{
Renata Manconi \\ Dipartimento di Medicina Veterinaria, Università di Sassari, Via Vienna 2, 07100, \\ Sassari, Italy
}

\begin{abstract}
Invasions of alien species form one of the major threats to global biodiversity. Among planarian flatworms many species are known to be invasive, in several cases strongly affecting local ecosystems. Therefore, a detailed knowledge on the biology of an invasive species is of utmost importance for understanding the process of invasion, the cause of its success, and the subsequent ecological impact on native species. This paper provides new information on the biology of introduced populations of the freshwater flatworm Girardia tigrina (Girard, 1850) from Europe. This species is a native of the Nearctic Region that was accidentally introduced into Europe in the 1920s. Since then, numerous records across the European continent bear witness of the invasiveness of this species, although only a few studies focused on the biology
\end{abstract}


of the introduced populations. We report on the morphology of sexualized individuals from a fissiparous Italian population, representing the second record of spontaneous sexualization of fissiparous individuals in this species. A detailed morphological account of the reproductive apparatus of these ex-fissiparous animals is presented. Our results increased the number of morphological groups previously recognized for European populations of G. tigrina, thus corroborating the hypothesis on multiple independent introductions to this continent. Karyological results obtained from our fissiparous Italian individuals revealed a constant diploid chromosome complement of sixteen chromosomes. Further, we document the marked intraspecific variation in several morphological features of this species.

\section{Keywords}

ectopic hyperplasic ovaries - ex-fissiparous Dugesiidae - Italian non-native species - morphotypes supernumerary copulatory apparatus

\section{Introduction}

Invasions of alien species are considered to be one of the major threats to global biodiversity and to form the second major cause of animal extinctions (Gherardi et al., 2007 and references therein). Among planarian flatworms or triclads many species are known to be invasive, in several cases strongly affecting local ecosystems (cf. Sluys, 2016). Therefore, detailed knowledge on the biology of an invasive species is of utmost importance for understanding the process of invasion, the cause of its success, and the subsequent ecological impact on native species (Ducey et al., 2005; Boll et al., 2015). To this end, we provide in this paper further insights into the biology of introduced populations of the freshwater flatworm Girardia tigrina (Girard, 1850).

Girardia tigrina is a widespread, native species of the Nearctic Region that has been accidentally introduced into Europe since the 1920s, very likely through the international trade in aquatic plants and the activity of aquarists. Subsequently, it has been recorded also for South America, Israel, Japan, and Australia (Marcus, 1946; Gourbault, 1969; Benazzi et al., 1970; Dahm \& Gourbault, 1978; Ball \& Reynoldson, 1981; Kawakatsu et al., 1985, 1993; Ribas et al., 1989; Benazzi, 1993; Sluys et al., 1995, 2005; Vila et al., 2004).

The first European record of this alien species was from Germany (Meinken, 1925), after which it was reported from France (De Beauchamp, 1946; Gourbault, 1969; Vila et al., 2004), Switzerland (Dahm, 1955), GreatBritain (Reynoldson, 1956), The Netherlands (Den Hartog, 1959), Luxembourg (Hoffmann, 1964), Iberian Peninsula and the Balearic Islands, Azores (Baguña et al., 1980; Ribas et al., 1989; Malhão et al., 2007; Vila-Farré et al., 2011 and references therein), and also from the Balkan peninsula from countries such as Romania (An der Lan, 1962; Babalean, 2018) and Herzegovina (Knezović et al., 2015). In the Italian peninsula, since the 1960 s populations of $G$. tigrina were recorded from many localities (Stagni \& Grasso, 1965; Stella \& Margaritora, 1966; Benazzi, 1981, 1993; Stocchino et al., 2013a). A fissiparous population of $G$. tigrina was very recently discovered in a river on the island of Sardinia, Italy (Stocchino, 2018).

In its native Nearctic Region G. tigrina is represented by sexual, asexual (fissiparous) 
and seasonally alternating sexual/asexual populations (Kenk, 1937). In contrast, the great majority of the allochthonous populations in other parts of the world is fissiparous (cf. Sluys et al., 2005).

Only a few $(\mathrm{n}=5)$ immigrant sexual populations were discovered until now, all occurring in Western Europe, viz. two populations from Great-Britain (Reynoldson, 1985; Gee et al., 1998), and single populations from Menorca Island (Spain) (Ribas et al., 1989), Italy (Benazzi, 1993), and France (Vila et al., 2004). The Italian sexual population was recorded from a lake in the southern part of the peninsula. Successive studies revealed a high degree of sterility of these Italian sexual specimens, despite the great number of cocoons that was laid (Benazzi \& Giannini Forli, 1996).

Among fissiparous populations of G. tigri$n a$, the occurrence of so-called "ex-fissiparous" individuals, i.e. planarians that stop multiplying by fission and acquire the sexual state, has been scarcely reported (cf. Grasso, 1974 and references therein; Ribas et al., 1989). Moreover, these very few records did not report details on the morphology of the reproductive apparatus of these "sexualized" animals.

Here we report (1) the occurrence of sexualized individuals of $G$. tigrina from a fissiparous Italian population, representing the second record for this species of spontaneous sexualization of fissiparous individuals; (2) a detailed morphological description of the reproductive apparatus of ex-fissiparous specimens of G. tigrina; (3) the chromosome complement of the Italian population; (4) the marked intraspecific variation in several morphological features of this species; (5) some peculiarities of the hyperplasic ovaries as well as morphological aberrations of the reproductive apparatus in the Italian population. Possible means of dispersal and subsequent establishment of populations are discussed.

\section{Materials and methods}

\subsection{Collection and culturing}

Planarians $(\mathrm{n}=6)$ were first collected in December 2009 from a rounded tank $(\sim 3 \mathrm{~m}$ in diameter) localised outside of the greenhouse of tropical terrestrial plants at the Botanical Garden of the University of Genoa (Liguria, Northwestern Italy), harbouring fishes (redwhite carps) and aquatic plants, such as Nimphaea alba (L.), Nuphar lutea (L.) Sm., and Lemna sp. (fig. 1A-B). The Botanical Garden is located within the city's historical centre. More recently (May 2018), in two other tanks planarians were found on the underside of semi-submerged leaves of $N$. alba: a) a small square tank $(\sim 60 \times 60 \mathrm{~cm}$, water depth $2 \mathrm{~cm})$, in which the planarians were associated with gastropods and larvae of insects; and b) a larger rounded tank $(\sim 3 \mathrm{~m}$ in diameter, water depth $10 \mathrm{~cm}$ ) in which the associated fauna were leeches and gastropods.

All individuals were exclusively fissiparous at collection, with signs of fission being visible. The collected specimens were transferred to the laboratory and were reared in glass bowls under semi-dark conditions at 18 $+/-2{ }^{\circ} \mathrm{C}$; the worms were fed weekly with fresh beef liver, while the bowls were cleaned within 8-12 $\mathrm{h}$ after feeding.

It was observed that in this culture, as well as in a strain of a Sardinian population (M. Pala \& G.A. Stocchino, pers. obs.), animals were extremely sticky, and that, for example, when they were attached firmly to the surface of the containers or to the paint brushes used, it was very difficult to remove the animals from these substrates.

\subsection{Morphology and karyology}

For morphological study, sexualized specimens were fixed for $24 \mathrm{~h}$ in Bouin's fluid, dehydrated in a graded ethanol series, then transferred to clove oil, and, subsequently, 
embedded in synthetic wax or paraffin. Serial sections were made at intervals of $8 \mu \mathrm{m}$ and stained with Mallory-Cason. Reconstructions of the copulatory complex were obtained by using a camera lucida attached to a compound microscope.

Chromosome metaphasic plates were obtained by the squashing method on single caudal regenerative blastemas of 5 fissiparous specimens. Blastemas were first treated with a solution of colchicine $(0.3 \%)$ for $4 \mathrm{~h}$, then transferred onto glass slides and treated with a solution of acetic acid ( $5 \%$ ) for $5 \mathrm{~min}$. Subsequently, they were stained with acetic orcein for $2 \mathrm{~h}$ and squashed using a small coverslip. The chromosome complement was characterised on the basis of $5^{-6}$ metaphasic plates per specimen. Chromosomal nomenclature follows Levan et al. (1964).

\subsection{Material examined}

ZMA V.Pl. 7283.1, freshwater tank at the Botanical Garden of the University of Genoa (44 ${ }^{\circ} 25^{\prime} 35^{\prime \prime} \mathrm{N}, 8^{\circ} 54^{\prime} 54^{\prime \prime}$ E) Genoa, Italy, December 2009, coll. Paola Ramoino and Renata Manconi, sagittal sections on 4 slides; CGAS Pla 18.1, ibid., sagittal sections on 3 slides; CGAS Pla 18.2, ibid., sagittal sections on 3 slides.

The material is deposited in the collections of Naturalis Biodiversity Center, Leiden, The Netherlands (ZMA collection code), and in the Giacinta A. Stocchino collection (CGAS), University of Sassari.

\subsection{Abbreviations used in the figures}

a, atrium; b, brain; ba, blind atrium; bc, bursal canal; bro, branch of right oviduct; ca, common atrium; cb, copulatory bursa; cg, cement glands; cm, circular muscles; csv, common seminal vesicle; di, diverticulum; dp, diplotene oocytes; e, eye; ec, ectopic hyperplasic ovaries; ed, ejaculatory duct; g, gonopore; h, head; ho, hyperplasic ovaries; lm, longitudinal muscle; lvd, left vas deferens; m, mouth; ma, male atrium; o, oviduct; og, oogonia; pb, penis bulb; ph, pharynx; php, pharyngeal pocket; pp, penis papilla; rbc, right bursal canal; ro, right oviduct; s, sperm; sba, supplementary blind atrium; sd, spermatids; sg, shell glands; sp, supplementary penis; spv, spermiducal vesicles; st, spermatogonia; sv, seminal vesicles; vd, vas deferens.

\section{3}

\section{Results}

\subsection{Sexualization}

From the animals obtained during the first collection three specimens sexualized, after having been kept in the laboratory for about five years, during which also fissioning occurred. These sexualized animals displayed the characteristic features of ex-fissiparous individuals: large body size, development of the copulatory apparatus, hyperplasic ovaries. Four cocoons were also laid, one of which was found opened, but no juveniles were observed.

\subsection{Morphological description}

Body size of preserved, sexualized specimens ranged from 4 to $6 \mathrm{~mm}$ in length and 1.2-2 $\mathrm{mm}$ in width. Head triangular, with bluntly pointed anterior tip. Two eyes are present in the middle of the head at the level of auricles, positioned close together and located in broad pigment-free patches. Unpigmented auricular grooves are marginally placed just posteriorly to the eyes (fig. $1 \mathrm{C}$ ).

The dorsal pigmentation pattern is of the "striped type" (sensu Hyman, 1939): on the yellowish-brown background colour run two longitudinal stripes, made up of black spots, separated by a lighter yellowish-brown middorsal band; further there are also black specks haphazardly distributed on the dorsal surface, while a clear zone runs along the entire body margin (fig. $1 \mathrm{C}$ ). 

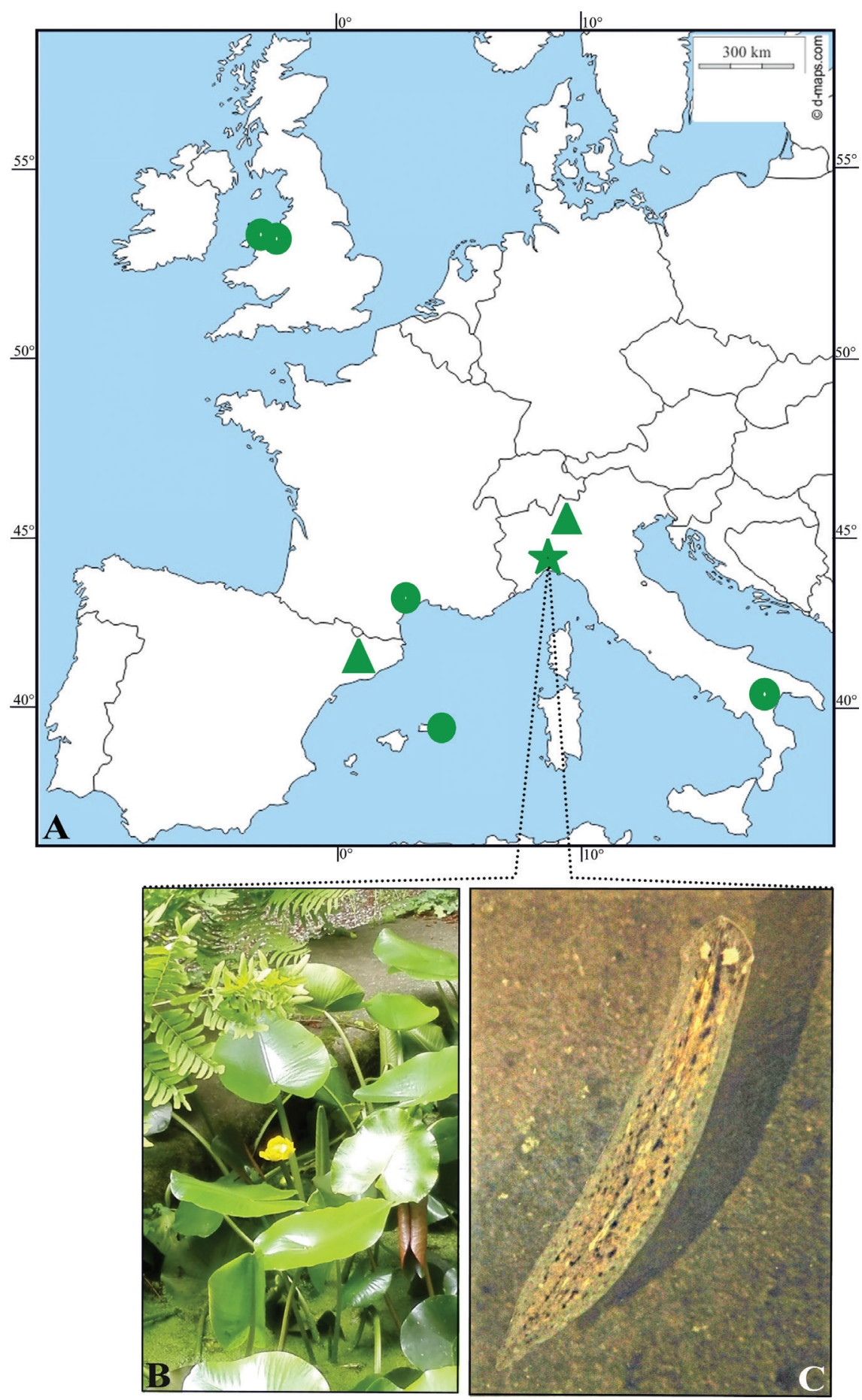

FIGURE 1 Girardia tigrina. A. Geographic range of allochthonous sexual populations (filled circles) and populations with sexualized animals (triangles and asterisk) in the Western Palaearctic; asterisk: population from Liguria investigated in the present study. B. Aquatic plants as preferential shaded microhabitat in a tank at the Botanical Garden of the University of Genoa, Liguria. C. Habitus of a living ex-fissiparous specimen of the Ligurian population. Scale bar not available. 
The pharynx is unpigmented, with the inner and outer pharyngeal musculature bilayered, i.e. without an extra, third, outer longitudinal muscle layer. The position of the mouth opening is different in the three specimens examined. In specimen ZMA V.Pl. 7283.1 the mouth is located at the hind end of the pharyngeal pocket (fig. 2A), whereas in specimens CGAS Pla 18.1 and CGAS Pla 18.2 the mouth opening is shifted anteriad, in that it is located at about $1 / 6$ and $1 / 4$, respectively, of the distance between the posterior end of the pharyngeal pouch and the root of the pharynx (fig. $2 \mathrm{~B}, \mathrm{C}$ ).

The ovaries are hyperplasic in all three specimens examined, with several scattered masses of oocytes and oogonia in the body region directly posterior to the brain, occupying almost the entire dorso-ventral space of the body (fig. 3A). All oocytes show a regular meiotic maturation process, from prophase up to the diplotene phase, when meiosis ends. Diplotene oocytes scattered in the ovarian masses do not show degenerative nuclear or cytoplasmic stages (fig. ${ }_{3} \mathrm{C}$ ). Moreover, in specimen ZMA V.Pl. 7283.1 some ovarian masses are located ventrally on the right-hand side of the copulatory apparatus, that is, far into the posterior part of the body (fig. $3^{B}$ ). Also in these ovarian masses no anomalies in the oocytes were observed.

The anterior portion of the oviducts is expanded to form a seminal receptacle or ampulla, which communicates with the ovarian masses at a variable position, depending on the hyperplasic condition of the ovaries.

The infranucleated oviducts run ventrally in caudal direction to the level of the copulatory apparatus and then curve dorsad towards the vaginal area, subsequently opening symmetrically into the angled hind part of the bursal canal (figs 4A, 5).

The testes are situated ventrally and extend from the level of the most caudal postcephalic ovarian masses into the posterior end of the body. The follicles are well developed in
ZMA V.Pl. 7283.1 and CGAS Pla 18.1, whereas they are under-developed in specimen CGAS Pla 18.2. In the mature testes spermatogenesis appears to proceed in a regular fashion, in that no anomalies, such as irregularly shaped spermatids or spermatozoa, were observed (fig. $3 \mathrm{D}$ ). Vitellaria are located, as usual, between the intestinal branches.

In ZMA V.Pl. 7283.1 two copulatory apparatuses are present in the post-pharyngeal region: the fully developed system as well as another, second one, the latter located at a short distance behind the pharyngeal pocket. This second copulatory apparatus is not completely developed and consists of only a dorso-ventrally oriented penis.

A single, left vas deferens can be observed penetrating the muscular penis bulb of the incompletely developed, second copulatory apparatus. The penis bulb consists of loosely interwoven layers of circular and longitudinal muscle fibres. In this not fully developed system, the sperm duct enlarges to form a seminal vesicle, which continues as a very short ejaculatory duct that opens at the tip of the papilla. The ovoid penis papilla is covered by a partially infranucleated epithelium, which is underlain by a subepithelial layer of circular muscle, followed by a layer of longitudinal muscle fibres. The penis papilla is housed in a genital atrium, which is lined by a cuboidal, partially infranucleated epithelium, surrounded by a subepithelial layer of circular muscles, followed by a layer of longitudinal muscle fibres. The genital atrium is not divided into a male and common atrium and does not communicate ventrally with a proper gonopore (figs 4A, 6A).

Posterior to this incompletely developed copulatory apparatus lies the main, welldeveloped apparatus (figs 4A, 6A). The following description is based on the fully developed copulatory apparatus of ZMA V.PI. 7283.1 and on those of CGAS Pla 18.1 and CGAS Pla 18.2. 



FIGURE 2 Girardia tigrina from Liguria. Photomicrographs of the pharynx; sagittal sections (anterior to the left). A. ZMA V.Pl. 7283.1, mouth opening located at the hind end of the pharyngeal pocket; B. CGAS Pla 18.1, mouth opening located at about $1 / 6$ of the distance between the posterior end of the pharyngeal pouch and the root of the pharynx; C. CGAS Pla 18.2, mouth opening located about at $1 /{ }_{4}$ of the distance between the posterior end of the pharyngeal pouch and the root of the pharynx. 

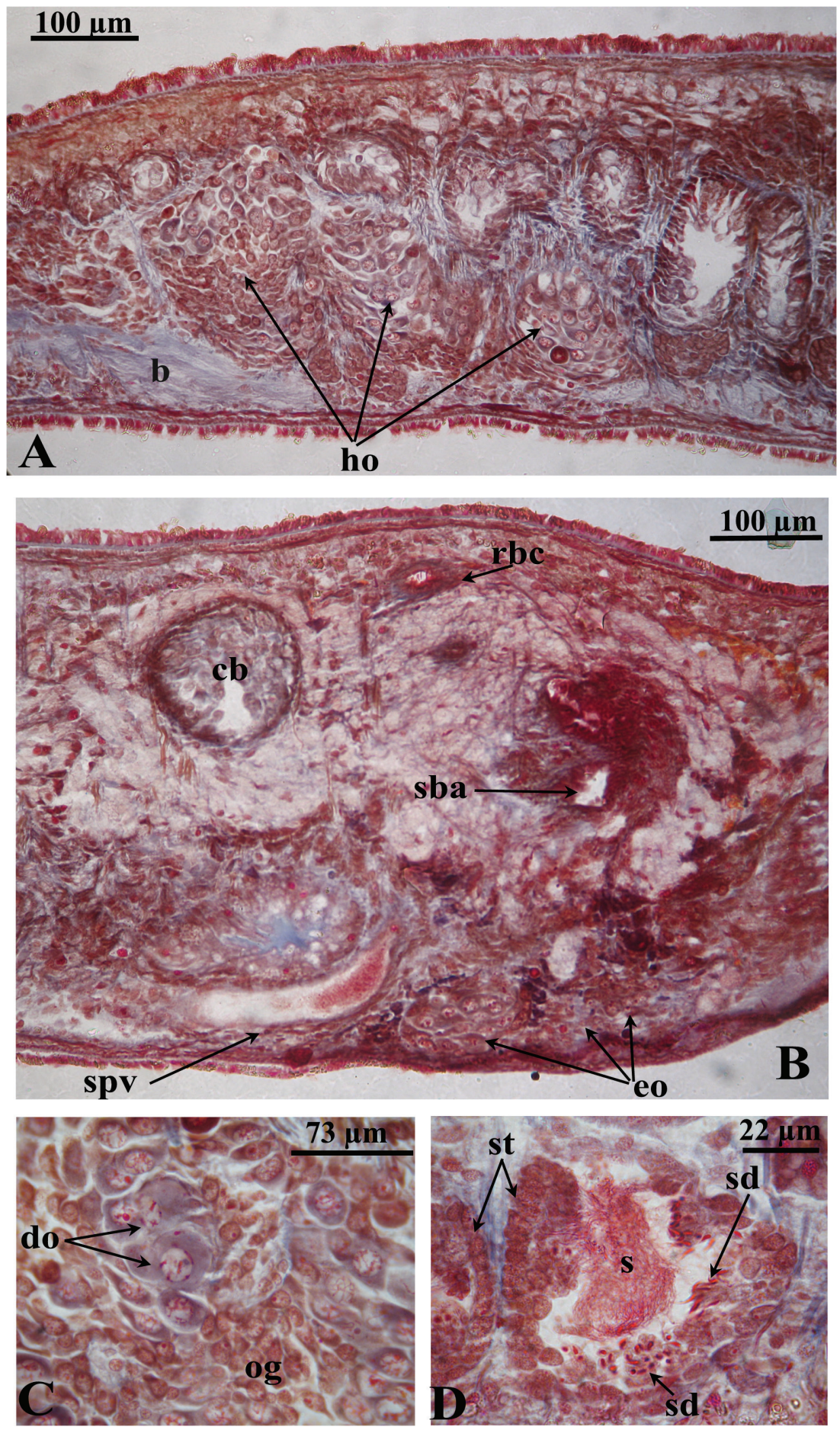

FIGURE 3 Girardia tigrina from Liguria. Photomicrographs of hyperplasic ovaries and testes. A. ZMA V.Pl. 7283.1, hyperplasic ovaries located behind the brain; B. ZMA V.Pl. 7283.1, ectopic hyperplasic ovarian masses located at the level of the copulatory apparatus; C. ZMA V.Pl. 7283.1, magnification of hyperplasic ovaries, with oocytes at different stages of maturation; D. ZMA V.Pl. 7283.1, mature testes with sperm. 



$140 \mu \mathrm{m}$

FIGURE 4 Girardia tigrina from Liguria. ZMA V.Pl. 7283.1 A. sagittal reconstruction of the two copulatory apparatuses (anterior to the left); B. sagittal reconstruction of the main copulatory apparatus at the level of the right branch of the bursal canal and the blind cavity (anterior to the left).

The small sac-shaped copulatory bursa is lined by a columnar, glandular epithelium bearing basal nuclei and it is surrounded by a network of muscle fibres. The copulatory bursae of the three specimens examined contain no spermatophores.

As usual, the bursal canal runs in a caudal direction to the left of the copulatory apparatus. The posterior portion of the bursal canal curves sharply towards the ventral body surface (thus constituting the so-called "angled" bursal canal), and at this point receives the separate, symmetrical openings of the oviducts, while, subsequently, it communicates with the common atrium. The bursal canal is lined by cuboidal, nucleated, and ciliated cells and is surrounded by a subepithelial layer of circular muscles, followed by a layer of longitudinal muscle (figs 4-6).

Shell glands, producing a fine-grained, erythrophil secretion, which is very abundant






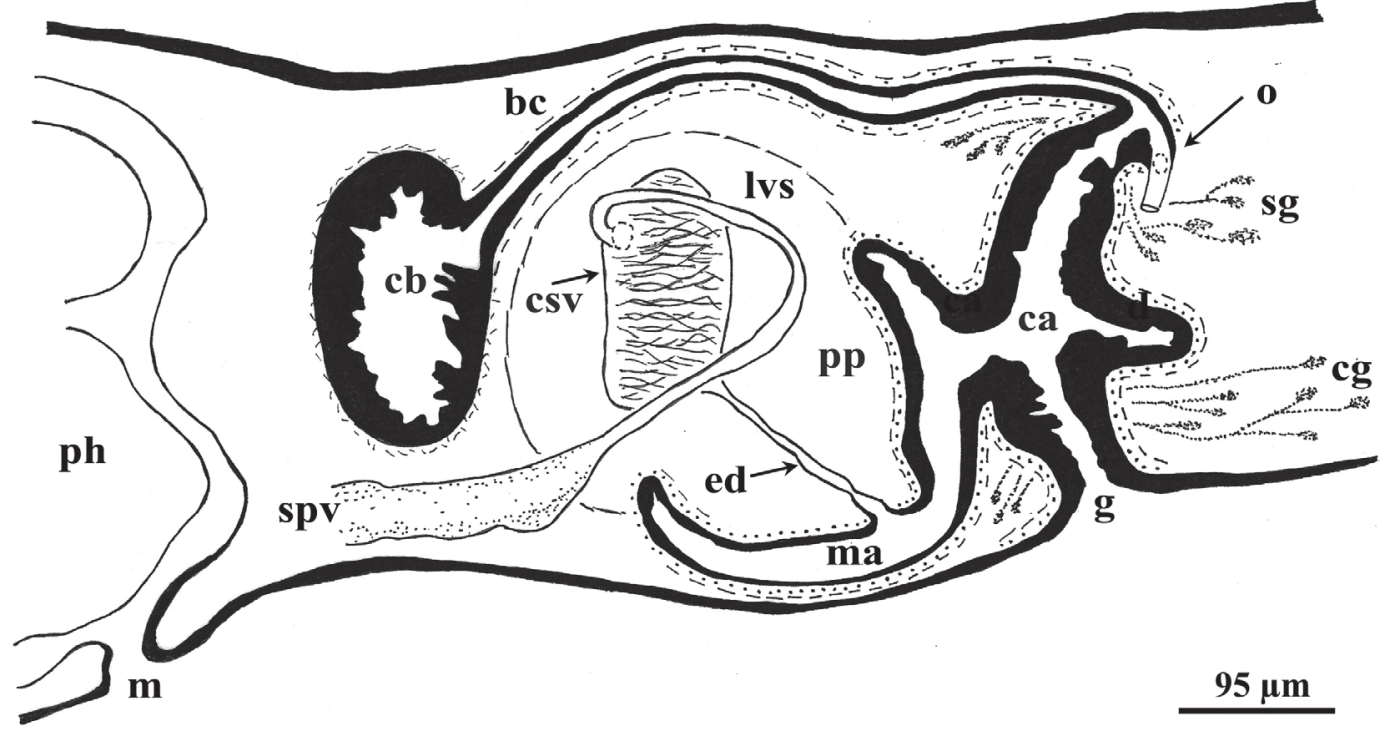

FIGURE 5 Girardia tigrina from Liguria. CGAS Pla 18.1, sagittal reconstruction of the copulatory apparatus (anterior to the left).

18.1, open into the bursal canal just ectally, i.e. ventrally to the separate openings of the oviducts.

From the bursal canal of specimen ZMA V.Pl. 7283.1 originates a left branch at a short distance from the postero-dorsal wall of its bursa that, subsequently, curves downward to communicate with a blind sac or cavity located on the left side of the body; this cavity may be considered to represent a small, additional genital atrium.

This blind cavity is lined by an infranucleated epithelium that is underlain by a subepithelial layer of longitudinal muscle fibres and receives the openings of several cement glands (fig. 4B). At the level of the posteriorly located ectopic ovaries, from the right oviduct originates a dorsal branch, which ascends to the supernumerary left branch of the bursal canal and then opens into it just at the point where the canal opens into the blind additional atrium. Shell glands open into this oviduct just before the duct opens into the bursal canal.

The penis bulb is large and globose in ZMA V.Pl. 7283.1 and CGAS Pla 18.1, whereas it is only moderately developed in CGAS Pla 18.2, consisting of loosely interwoven layers of circular and longitudinal muscle fibres (figs 4-6).

The sperm ducts form well-developed spermiducal vesicles, packed with sperm, in specimens ZMA V.Pl. 7283.1 and CGAS Pla 18.1. In ZMA V.Pl. 7283.1 and CGAS Pla 18.2, the vasa deferentia at first curve dorsad before symmetrically penetrating the anterior wall of the penis bulb. In its ascending course, the left vas deferens of ZMA V.Pl. 7283.1 forms a closed loop (fig. 4A). In CGAS Pla 18.1 the vasa deferentia recurve considerably in caudal direction before separately and symmetrically penetrating the antero-dorsal wall of the penis bulb (fig. 5). Once inside the penis bulb, each vas deferens enlarges to form a wide vesicle in ZMA V.Pl. 7283.1, whereas the ducts fuse to form a single intrabulbar vesicle in CGAS Pla 18.1 and CGAS Pla 18.2.

In all specimens the seminal vesicle(s) continue as a single ejaculatory duct that opens at the tip of the penis papilla. In ZMA V.Pl. 7283.1 the ejaculatory duct follows a basically ventral course through dhe papillả, whereaśite ss thore.2PM 



FIGURE 6 Girardia tigrina from Liguria. Photomicrographs of the copulatory apparatus; sagittal sections. A. ZMA V.Pl. 7283.1, supernumerary penis and the main, fully developed copulatory apparatus; B. CGAS Pla 18.1, copulatory bursa with the bursal canal, penis, male atrium, and common atrium with diverticulum; C. CGAS Pla 18.2, copulatory bursa with the bursal canal, penis, and male atrium. 
centrally located in CGAS Pla 18.1 and CGAS Pla 18.2 (figs 4-6). In CGAS Pla 18.2 the ejaculatory duct is very short.

In all specimens examined the intrabulbar seminal vesicles, including that of the supernumerary penis in ZMA V.Pl. 7283.1, are filled with a longitudinally oriented web-like fibrillate secretion. In CGAS Pla 18.2 many erythrophil granules are also present in the seminal vesicle (figs 4-6).

In ZMA V.Pl. 7283.1 the penis papilla has the shape of an elongated cone; in CGAS Pla 18.1 it is a stubby cone, while it is barrel-shaped and more dorso-ventrally oriented in CGAS Pla 18.2 (figs 4-6). The penis papilla is covered by an infranucleated epithelium in ZMA V.Pl. 7283.1 and CGAS Pla 18.1, but in CGAS Pla 18.2 it is provided with a nucleated epithelium. The epithelium of the papilla is underlain with a subepithelial layer of circular muscle fibres, followed by a layer of longitudinal muscles.

In CGAS Pla 18.1 and CGAS Pla 18. 2 the genital atrium is clearly divided into a common atrium and a male atrium, which communicate via a pronounced narrowing. In ZMA V.Pl. 7283.1 this division into two atria is less obvious, very likely due to the elongation of the penis papilla, which occupies the entire common atrium, with its tip extending into the gonopore (figs 4-6). The atria are lined by an infranucleated epithelium, which is underlain by a subepithelial layer of circular muscle, followed by a layer of longitudinal muscle fibres. The common atrium opens ventrally through the gonopore and it receives the coarsely granular, xanthophil secretion of very abundant cement glands in ZMA V.Pl. 7283.1 and CGAS Pla 18.1, while in CGAS Pla 18.2 these glands are only moderately developed (figs 4-6). In CGAS Pla 18.1 a well-developed posterior diverticulum is present in the hind wall of its common atrium, whereas in ZMA V.Pl. 7283.1 and CGAS Pla 18.2 this diverticulum is much less pronounced (figs 4-6).

\subsection{Karyology}

Metaphasic plates revealed that the fissiparous animals are characterized by a constant diploid set of 16 chromosomes with $n=8$ as haploid number (fig. 7). The karyotype consists of 8 pairs of metacentric chromosomes in descending order, with the first four chromosomes being metacentric isobrachial, while the other chromosomes are metacentric heterobrachial, with the exception of chromosome 8 , which is at the border between metacentric and submetacentric.

\section{$4 \quad$ Discussion}

\subsection{Reproductive modes and sexualization process}

Sexualization of individuals from fissiparous strains of freshwater planarians has been highlighted since the early 1970s for species of the genus Dugesia (cf. Benazzi, 1974). These planarians were called "ex-fissiparous" and are characterized by (a) an increase in body dimensions, (b) development of a complete copulatory apparatus, (c) hyperplasic ovaries, (d) underdeveloped testes, and (e) sterility or, at least, low fertility (cf. Stocchino et al., 2012, 2014; Harrath et al., 2013, 2014).

Only a few cases of sexualized individuals from fissiparous strains of $G$. tigrina have been documented (Grasso, 1974 and references therein; Ribas et al., 1989). Grasso (1974) obtained sexualization of many fissiparous individuals from a north-Italian population (Lake Maggiore), but only after the worms had been fed for many weeks with crushed tissues of sexually mature specimens of Polycelis nigra (Müller, 1774). Typical hyperplasic ovaries were reported for these ex-fissiparous animals. It is noteworthy that this worker did not succeed in obtaining sexualized animals from this population when the flatworms were fed for more than ten years with the usual live Tubifex worms or with minced beef. 

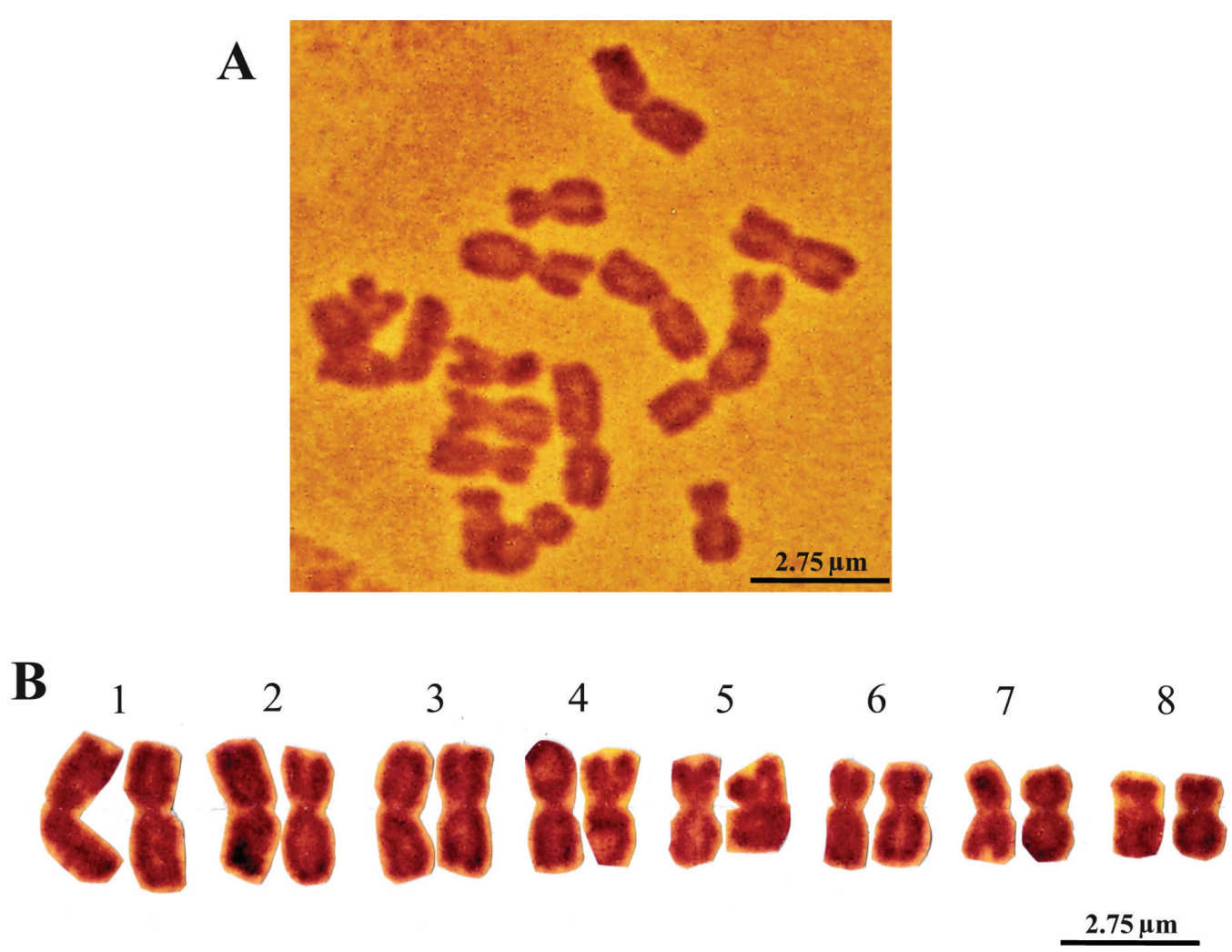

FIGURE 7 Girardia tigrina from Liguria. A. Metaphasic plate; B. Karyogram.

Many years later, Ribas et al. (1989) reported on some rare, large ex-fissiparous individuals from Spanish mainland populations, which never laid cocoons. However, these Spanish specimens were of the spotted morphotype (see below, under "Spotted vs. striped morphotypes" section) with strongly and coarsely pigmented pharynx, in contrast to the Italian animals that we examined, which belong to the striped morphotype with unpigmented pharynx. Unfortunately, both Grasso (1974) and Ribas et al. (1989) did not provide any details on the reproductive apparatus of their sexualized planarians. The present paper provides the first detailed description of exfissiparous individuals of G. tigrina.

It is noteworthy that in one of the our animals examined an extra, albeit incomplete, copulatory apparatus is present, as well as a doubling of some structures in the main, completely developed apparatus, together with an unusual course of the left vas deferens. It is interesting to note that with respect to the genus Girardia occurrence of supernumerary copulatory apparatuses was reported for G. dorotocephala (Woodworth, 1897) by Kenk (1935). This worker described that 17 out of 71 fissiparous specimens from a particular locality, which were kept at a constant low temperature and were fed with beef liver, developed 2-4 genital pores. These animals were on average larger than those with one genital pore, while they also had a comparatively larger post-pharyngeal region as compared with the single-gonopore specimens. Three specimens (with 4, 3, and 2 gonopores, respectively) that 
Kenk (1935) examined histologically showed normal testes, hyperplasic ovaries, and multiple copulatory apparatuses, developed to greater or lesser extent and sometimes connected to each other, being arranged one behind the other along the anterior-posterior axis of the body. After sexualization also cocoons were laid.

Supernumerary sexual structures were also induced by low temperature in a laboratory strain of Dugesia gonocephala (presently D.japonica) from Japan (Ogukawa, 1955). However, differently from the Girardia species these aberrations occurred only in sexual animals with normal ovaries and testes.

A peculiar condition encountered in the present study is that besides hyperplasic ovaries, located as usual just behind the brain, in the aberrant specimen ectopic ovarian masses are localized ventrally at the level of the copulatory apparatus, thus very far from the usual anterior position. Such a very peculiar phenomenon has never been reported before for freshwater triclads.

It is surprising that in this case neoblasts not destined to become germ cells were instead induced toward this kind of differentiation. In point of fact, it has been demonstrated that the nanos gene is required for postembryonic development, regeneration, and maintenance of planarian germ cells (cf. Newmark et al., 2008 and references therein). However, also in fissiparous animals nanos-positive cells were detected at positions in which germ cells are first observed post-embryonically in sexual planarians and, thus, they were considered to be "presumptive germ cells" that are unable to complete their differentiation (cf. Newmark et al., 2008 and references therein).

It is known that environmental factors, especially temperature, influence sexual or asexual reproduction in populations with alternating reproductive modes (Kenk, 1937). Moreover, sexualization of our G. tigrina and the G. dorotocephala studied by Kenk (1935) was not induced by food items consisting of pieces of sexual planarians, which may have supplied sex-inducing substances, as has occurred in certain experiments (see Grasso \& Benazzi, 1973; Sakurai, 1981). Thus, it may be that under laboratory conditions (constant temperature and lighting and regular food supply) in the usual ex-fissiparous animals, at least in the genus Girardia, sometimes an extra sexual induction occurs with the effect that besides development of supernumerary sexual structures also neoblasts not belonging to presumptive germ cells are able to differentiate into germ cells.

Hyperplasic ovaries in ex-fissiparous individuals have been reported for a number of Dugesia species (De Vries, 1986; Pala et al., 1995; Stocchino et al., 2002, 2009, 2012, 2013b, 2014, 2017; Harrath et al., 2013). In contrast, exfissiparous individuals of $D$. benazzii Lepori, 1951 and D. etrusca Benazzi, 1946 do not develop hyperplasic ovaries (Stocchino \& Manconi, 2013).

Such hyperplasic ovaries are characterised by degenerative processes, which lead to a blockage of the maturation of the oocytes (Gremigni \& Banchetti, 1972a). It has been demonstrated that a complex process of early autophagy, followed by apoptotic processes, occurs during the cell death of oocytes in the hyperplasic ovaries of $D$. arabica and that cytokine-like molecules may contribute to this pathology (Harrath et al., 2014, 2017).

As in species of the genus Dugesia occurrence of hyperplasic ovaries has been considered to be the result of a greater proliferation of neoblasts into oogonia (Gremigni \& Banchetti, 1972b; Benazzi, 1974), we may surmise that the same process also produced the hyperplasia in the ectopic ovaries.

Another peculiarity, evident in all three G. tigrina specimens examined, concerns the fact that, notwithstanding the hyperplasic condition, oogenesis appears regular and the hyperplasic ovaries lack the typical 
degenerative stages that are characteristic of such sexualized specimens in several Dugesia species (Gremigni \& Banchetti, 1972a; Stocchino et al., 2009, 2012, 2013b; Harrath et al., 2014, 2017).

Furthermore, in the aberrant individual, and also in another specimen examined, testes are also well-developed, exhibiting all phases of sperm maturation. That spermatogenesis is regular is also highlighted by (1) the presence of sperm inside the vasa deferentia, of which the posterior tracts are enlarged as spermiducal vesicles, and (2) the presence of allosperm in the oviducts, indicating previous mating(s) with another animal(s).

The regular female and male gametogenesis may be related to the eudiploid condition of the Italian population (see below), in that it allows a more regular meiosis and that, thus, potential sexual reproduction cannot be ruled out, although no juveniles were observed to hatch from the opened cocoon of these sexualized animals.

With respect to sexualized freshwater planarians, only one case of well-developed testes has been reported, namely for $D$. bifida, albeit that in this species the ovaries are only weakly hyperplasic. Furthermore, in this species the chromosome complement is eudiploid, while sexualized animals laid fertile cocoons (Stocchino et al., 2014). In contrast, the majority of the fissiparous species of the genus Dugesia are triploid or mixoploid, with the sexualized specimens exhibiting gonadal anomalies (Stocchino et al., 2014).

The presence of a fibrillate secretion in the seminal vesicles has never been reported for G. tigrina and may be compared with the "web-like tissue" described by Hyman (1956) for D. diabolis (presently G. dorotocephala (Woodworth, 1897)) and later also reported by Ball (1971) and Chen et al. (2015) for G. dorotocephala and G. sinensis Chen \& Wang, 2015, respectively. Probably it results from the mixing up of "....a secretion of some sort ...." (Ball, 1971, p. 15) and sperm that is also present in the seminal vesicle (Chen et al., 2015).

\subsection{Karyology}

Our karyologycal analysis revealed a constant diploid chromosome complement $(2 \mathrm{n}=16$; $\mathrm{n}=$ $8)$. The basic haploid complement of 8 chromosomes is in agreement with previous studies (cf. Benazzi \& Benazzi-Lentati, 1976; Kawakatsu et al., 1981; Ribas et al., 1989; Benazzi, 1993). While for sexual populations only diploid karyotypes have been reported, fissiparous populations show diploid, triploid or mixoploid (diploid and triploid) karyotypes (Dahm, 1958; Benazzi \& Benazzi-Lentati, 1976; Kawakatsu et al., 1981; Ribas et al., 1989; Benazzi, 1993).

That all chromosomes in our specimens examined are metacentric is in agreement with previous data on European populations (Ribas et al., 1989 and references therein). In contrast, for several non-European populations karyotypes were reported that consisted of 7 pairs of metacentric chromosomes and one pair of submetacentric chromosomes (the $6^{\text {th }}$ chromosome set): (1) a sexual population from Canada (Puccinelli \& Deri, 1991); (2) sexual and asexual populations from South Brazil (Kawakatsu et al., 1981); (3) asexual populations from Japan (Kawakatsu et al., 1985, 1993; Tamura et al., 1985).

\subsection{Intraspecific morphological variability}

Our results highlight the marked intraspecific morphological variability of several features of G. tigrina, such as: (a) pharynx pigmentation, being present or absent; (b) position of the mouth opening, which may be located at the hind end of the pharyngeal pocket or may be shifted anteriad (located at about $1 / 6$ or $1 / 4$ of the distance between the posterior end of the pharyngeal pouch and the root of the pharynx); (c) length of the ejaculatory duct, 
which may be long or very short; (d) number of the seminal vesicles, which may be single or double; (e) course of the vasa deferentia, which, before penetrating the antero-dorsal wall of the penis bulb, in some cases simply curve dorsad, while in other cases they recurve considerably in caudal direction. These features will be discussed below.

Although a pigmented pharynx was considered a diagnostic character for G. tigrina (cf. Kenk, 1972; Ball \& Reynoldson, 1981), further studies have also reported on specimens with unpigmented pharynx (Ribas et al., 1989; Benazzi, 1993). Nevertheless, Sluys (2001) considered the pigmented pharynx to be an apomorphic character for the genus Girardia, in spite of the fact that a few species are polymorphic, in that individuals may have either pigmented or unpigmented pharynges, and very few have an unpigmented pharynx. Our finding of specimens with unpigmented pharynx thus confirms the variability of this character.

The position of the mouth opening was considered a feature that warranted further consideration, since the mouth was found to be at different positions in the pharyngeal pocket of animals from different geographic localities (Sluys et al., 2005). However, this variability appears to be much less due to a geographic gradient than to intraspecific variation, as in our three animals from Italy the location of the mouth turned out to be highly variable, even within a single population.

Presence of two seminal vesicles in one of our individuals and a single intrabulbar vesicle in the other two individuals confirms previous reports on the variability of this character (cf. Kenk, 1972; Ribas et al., 1989). According to Kenk (1972), a single seminal vesicle would be a transitory condition, but we interpret it as being the result of intraspecific variation.

The seminal vesicle(s) may continue either as a long ejaculatory duct or as a very short duct, both conditions having been reported in the present paper and also in earlier studies (e.g. Ball, 1971, figs 5, 7; Kenk, 1972; Kawakatsu \& Mitchell, 1981).

Another character showing marked differences among populations concerns the arrangement of muscles around the bursal canal. Sluys et al. (2005) suggested that the Nearctic and Neotropical forms of G. tigrina concern sibling species, in view of the fact that South American populations have a bursal canal musculature consisting of a well developed coat of intermingled circular and longitudinal muscle fibres, whereas North American forms are characterised by a simple coat of muscle around the bursal canal made up by a thin, subepithelial layer of circular muscle, followed by an equally thin layer of longitudinal muscle. The latter condition was found also in introduced populations, such as those from Spain, France, southern Italy (Ribas et al., 1989; Vila et al., 2004; Sluys et al., 2005), and our population from Liguria, northern Italy. This may be an indication that all of the above-mentioned introduced European populations originate from the Nearctic Region.

\subsection{Spotted vs. striped morphotypes}

With respect to its external features, G. tigrina is a polymorphic species that varies from spotted to striped, both types of individuals sometimes occurring in the same population in its native area (Kenk, 1972). Several of these conditions are expressed also in European populations: 1) all sexual populations are of the striped type (Ribas et al., 1989; Benazzi, 1993; Gee et al., 1998; Vila et al., 2004); 2) the majority of fissiparous populations are spotted without exhibiting sexualization processes (i.e. producing ex- fissiparous animals) (cf. Ribas et al., 1989 and references therein); 3) a single case of a fissiparous striped population and with development of ex-fissiparous specimens (present paper); 4) some fissiparous 
spotted populations exhibiting sexualization processes (Grasso, 1972, 1974; Ribas et al., 1989).

Ribas et al. (1989) related the external pigmentation pattern of several Spanish populations with the pharynx pigmentation, thus distinguishing three morphological classes: A, fissiparous "spotted" with pigmented pharynx; B, fissiparous "spotted" with unpigmented pharynx; C, sexual, "striped" with unpigmented pharynx. Class A and the group made by classes $B$ and $C$ together were considered as natural groups or races, also on the basis of biochemical data. To these classes we can now add a fourth class, comprising the Ligurian fissiparous, "striped" population with unpigmented pharynx.

The presence in Europe of several morphological groups may be explained as the result of multiple independent introductions of $G$. tigrina to this continent, very likely from the Nearctic Region (see above), as already suggested by Ribas et al. (1989) for the Spanish populations. Future molecular analyses might form appropriate tests of this hypothesis.

\subsection{Dispersal and establishment of populations}

Many underlying causes have been suggested for the remarkable dispersal and establishment capability of G. tigrina, such as (a) fissiparous reproduction, enabling it to rapidly colonize new water bodies (Wright, 1987), (b) extreme tolerance to suboptimal and demanding environmental conditions, allowing it to spread along water bodies which are denied to native species (Wright, 1987), (c) ability to exploit a wide variety of food resources with overlap in the diets of $G$. tigrina and native triclads, thus suggesting a potentially strong inter-specific competition for food (oligochaetes, isopods, chironomids, snails, caddisflies, mayflies, amphipods, and cladocerans) (Pickavance, 1971; Gee \& Yang, 1993), and (d) perhaps also cannibalism on other species of planarians such as Polycelis spp. and S. poly- chroa (Ball \& Reynoldson, 1981), and S. mediterranea (M. Pala \& G.A. Stocchino, pers. obs.) as this has been observed under laboratory conditions, and thus may imply strong competition with the native planarian fauna.

Another possible feature facilitating its spread over the world may be related to our observation that the animals are extremely sticky, which greatly enhances their accidental passive dispersal on, for example, aquatic plants. This may explain their occurrence in the botanical garden in Genoa.

Adhesiveness in flatworms is known to be facilitated by the secretion of adhesive glands. It is not known whether the observed stickiness of $G$. tigrina is due to an overproduction of mucus or to particular characteristics of the mucus released by the adhesive glands of this species. To our knowledge there are no comparative studies on this subject, which deserves further investigation.

\section{Acknowledgements}

This research was supported by the following grants to G.A. Stocchino: a grant in memory of Prof. N.G. Lepori (Università di Sassari), a Temminck Fellowship from Naturalis Biodiversity Center (Leiden, The Netherlands), and by a grant from Prof. R. Pronzato (Dipartimento di Scienze della Terra, dell'Ambiente e della Vita, Università di Genova). We acknowledge financial support from Fondazione di Sardegna and Regione Autonoma Sardegna (RAS2012-LR7/2007-CRP-60215" Conservazione e valorizzazione delle grotte sarde: biodiversità e ruolo socio-economico-culturale"). Prof. M. Pala is thanked for her kind support. We are grateful to Dr. P. Ramoino and Prof. G. Barberis (Dipartimento di Scienze della Terra, dell'Ambiente e della Vita, Università di Genova) and Dr. E. Mora (Botanical Garden of Genoa) for their kind help in collecting planarians and identification of plants. 
G.A. Stocchino, A.H. Harrath and L. Mansour extend their appreciation to the Deanship of Scientific Research at King Saud University for funding the work through the research group RG-164. Finally we want to thank Marta Riutort and two anonymous reviewers for their constructive comments.

\section{References}

An der Lan, H. (1962) Zur Turbellarien Fauna der Donau. Arch. Hydrobiol., suppl., 27, 3-27.

Babalean, A.F. (2018) On the freshwater tricladid flatworms (Platyhelminthes, Tricladida) in the urban areas of Craiova (Romania) - preliminary data. An. Univ. Craiova, 23, 275-285.

Baguña, J., Salò, E. \& Romero, R. (1980) Les planàries d'aigües dolces a Catalunya i a les illes Balears. I. Clau sistemàtica I distribució geogràfica. Butl. Inst. catal. Hist. nat., 45, 15-30.

Ball, I.R. (1971) Systematic and biogeographical relationships of some Dugesia species (Tricladida, Paludicola) from Central and South America. Am. Mus. Novit., 2472, 1-25.

Ball, I.R. \& Reynoldson T.B. (1981) British Planarians. Cambridge University Press, Cambridge.

Benazzi, M. (1974) Fissioning in planarians from a genetic standpoint. In: N.W. Riser \& M.P. Morse (Eds) Biology of the Turbellaria, pp. 476-492. McGraw-Hill, New York.

Benazzi, M. (1981) Nota sui Turbellari del Medio Po presso Caorso (PC). Riv. Idrobiol., 20, 167-171.

Benazzi, M. (1993) Occurrence of a sexual population of Dugesia (Girardia) tigrina, a freshwater planarian native to America, in a lake of southern Italy. Boll. Zool., 6o, 129-130. doi:10.1080/11250009309355799.

Benazzi, M. \& Benazzi Lentati, G. (1976) Platyhelminthes. In: B. John (Ed.) Animal Cytogenetics, Vol. 1, pp. 1-182. Gebr. Borntraeger, Berlin-Stuttgart.

Benazzi, M. \& Giannini Forli, E. (1996) Study on the reproductive biology of a sexual strain of the American freshwater planarian Dugesia
(Girardia) tigrina, found in southern Italy. Rend. Acc. Naz. Lincei, 7, 41-43.

Benazzi, M., Giannini, E. \& Puccinelli, I. (1970) Karyological research on the American planarians Dugesia dorotocephala and Dugesia tigrina.J. Biol. Psychol., 12, 81-82.

Boll, P.K., Rossi, I., Amaral, S.V. \& Leal-Zanchet, A. (2015) A taste for exotic food: Neotropical land planarians feeding on an invasive flatworm. PeerJ, 3, e1037. doi:10.7717/peerj.1307.

Chen, X-M., Chen, Y-H., Wu, C-C. \& Wang, A-T. (2015) A new species of the genus Girardia (Tricladida: Dugesiidae) from China. Zool. Syst., 40, 166-178.

Dahm, A.G. (1955) Dugesia tigrina (Girard) an American immigrant into European freshwaters. Proc. Int. Assoc. Theor. Appl.Limnol., 12, 554-561.

Dahm, A.G. (1958) Taxonomy and Ecology of Five Species Groups in the Family Planariidae. (Turbellaria, Tricladida, Paludicola). Nya Litografen, Malmö.

Dahm, G.A. \& Gourbault, N. (1978) Tricladida et Temnocephalida (Turbellaria). In: J. Illies (Ed) Limnofauna Europaea, pp. 16-20. Fischer, Stuttgart.

De Beauchamp, P. (1946) Présence en France d'une planaire américaine. Bull. Soc. Zool. France, 71, 210-212.

Den Hartog, C. (1959) Dugesia tigrina, an immigrant Triclad in the Netherlands. Biol. Jb. Dodonaea, 27, 68-72.

De Vries, E.J. (1986) On the taxonomic status of Dugesia gonocephala and Dugesia subtentaculata (Turbellaria, Tricladida, Paludicola).J. Zool. (Lond.), 209, 43-59.

Ducey, P.D., West, L-J., Shaw, G. \& De Lisle, J. (2005) Reproductive ecology and evolution in the invasive terrestrial planarian Bipalium adventitium across North America. Pedobiologia, 49, 367377. doi:10.1016/j.pedobi.2005.04.002.

Gee, H. \& Young, J.O. (1993) The food niches of the invasive Dugesia tigrina (Girard) and indigenous Polycelis tenuis (Ijima) and P. nigra (Müller) in two British lakes. Hydrobiologia, 254, 99-106.

Downloaded from Brill.com04/26/2023 12:53:42PM via free access 
Gee, H., Pickevance, I.R. \& Young, J.O. (1998) A comparative study of the population biology of the American immigrant triclad, Dugesia tigrina (Girard) in two British lakes. Hydrobiologia, 361, 135-143.

Gherardi, F., Bertolino, S., Bodon, M., Cesellato, S., Cianfanelli. S., Ferraguti, M., Lori, E., Mura, G., Nocita, A., Riccardi, N., Rossetti, G., Rota, E., Scalera, R., Zerunian, S. \& Tricarico, E. (2007) Animal xenodiversity in Italian inland waters: distribution, modes of arrival, and pathways. Biol. Invasions, 10, 435-454. doi:10.1007/ s10530-007-9142-9.

Gourbault, N. (1969) Expansion de Dugesia tigrina (Girard), planaire américaine introduite en Europe. Annal. Limnol., 5, 3-7. doi:10.1051/ $\operatorname{limn} / 1969006$.

Grasso, M. (1972) Ulteriori dati sull'induzione della sessualità in planarie di ceppo agamo nutrite con planarie sessuate. Boll. Zool., 39, 627-628.

Grasso, M. (1974) Some aspects of sexuality and agamy in planarians. Boll. Zool., 41, 379-393. doi:10.1080/11250007409430111.

Grasso, B. \& Benazzi, M. (1973) Genetic and physiologic control of fissioning and sexuality in planarians.J. Embryol. Exp. Morphol., 30, 317-328.

Gremigni, V. \& Banchetti, R. (1972a) Submicroscopic morphology of hyperplasic ovaries of exfissiparous individuals in Dugesia gonocephala s.l. Rend. Acc. Naz. Lincei, 52, 539-543.

Gremigni, V. \& Banchetti, R. (1972b) The origin of the hyperplasia in the ovaries of ex-fissiparous specimens of Dugesia gonocephala s.l. Rend. Accad. Naz. Lincei, 53, 477-485.

Harrath, A.H., Sluys, R., Aldahmash, W., Al-Razaki, A. \& Alwasel, S. (2013) Reproductive strategies, karyology, parasites, and taxonomic status of Dugesia populations from Yemen (Platyhelminthes, Tricladida, Dugesiidae). Zool. Sci., 30, 502-508. doi:10.2108/zsj.30.502.

Harrath, A.H., Semlali, A., Mansour, L., Ahmed, M., Sirotkin, A.V., Al Omar, S.Y., Arfah, M., Al Anazi, M.S., Alhazza, I.M., Nyengaard, J.R. \& Alwasel, S. (2014) Infertility in the hyperplasic ovary of freshwater planarians: the role of programmed cell death. Cell Tissue Res., 358, 607-620. doi:10.1007/s00441-014-1971-0.

Harrath, A.H., Semlali, A., Mansour, L., Aldamash, W., Al Omar, S.Y., Al Anazi, M.S., Nyengaard, J.R. \& Alwasel, S. (2017) Dynamics of Cytokine-like activity in the hyperplasic ovary of ex-fissiparous planarians. Biol. Bull., 232, 12-18. doi:10.1086/691408.

Hyman, L.H. (1939) North American triclad Turbellaria. IX. The priority of Dugesia Girard 1850 over Euplanaria Hesse 1897 with notes on American Species of Dugesia. Trans. Am. Microsc. Soc., 58, 264-275. doi:10.2307/3222879.

Hyman, L.H. (1956) North American triclad Turbellaria. 15. Three new species. Am. Mus. Novit., 1808, 1-14.

Hoffmann, J. (1964) Faune de Triclades Paludicoles du Grand-Duché de Luxembourg. Arch. Inst. Grd. Ducal Luxembourg, 30, 181-261.

Kawakatsu, M. \& Mitchell, R.W. (1981) A note on the morphology of Dugesia tigrina (Girard, 1850) from Louisiana, U.S.A. (Turbellaria, Tricladida, Paludicola).Proc.Jap. Soc. Syst.Zool., 2o, $1-6$.

Kawakatsu, M., Oki, I., Tamura, S. \& Yamayoshi, T. (1985) Reexamination of freshwater planarians found in tanks of tropical fishes in Japan, with a description of a new species, Dugesia austroasiatica sp. nov. (Turbellaria, Tricladida, Paludicola). Bull. Biogeogr. Soc. Japan, 40, 1-10.

Kawakatsu, M., Oki, I., Tamura, S., Yamayoshi, T., Hauser, J. \& Friedrich, S.M.G. (1981) Morphological, karyological and taxonomic studies of freshwater planarians from South Brazil VI. Dugesia tigrina (Girard, 1850) (Turbellaria, Tricladida, Paludicola). Bull. Fuji Women's Coll., No. 19, Ser II, 113-136.

Kawakatsu, M., Tamura, S., Takai, M., Yamamoto, K., Ueno, R. \& Oki, I. (1993) The first occurrence of a naturalized population of Dugesia tigrina (Girard, 1850) at Nagasaki, Kyûshû, Japan. Bull. Biogeogr. Soc. Japan, 48, 28-34.

Kenk, R. (1935) A morphological proof of the existence of zooids in Euplanaria dorotocephala. Physiol. Zool., 8, 442-456. 
Kenk, R. (1937) Sexual and asexual reproduction in Euplanaria tigrina (Girard). Biol. Bull., 73, 280-294.

Kenk, R. (1972) Freshwater planarians (Turbellaria) of North America. Biota of Freshwater Ecosystems, Identification Manual. Number 1. Environmental Protection Agency, Washington, U.S.

Knezović, L., Miliša, M., Kalafatić, M., Rajević, N. \& Planinić, A. (2015) A key to the freshwater triclads (Platyhelminthes, Tricladida) of Herzegovina watercourses. Period. Biol., 117, 425-433.

Levan, A., Fredga, K. \& Sandberg, A.A. (1964) Nomenclature for centromeric position. Hereditas, 52, 201-220.

Malhão, V., Raposeiro, P. \& Costa, A.C. (2007) The family Dugesiidae: new records for the Azorean Archipelago. Limnetica, 26, 331-340.

Marcus, E. (1946) Sôbre Turbellaria Brasileiros. Bol. Fac. Fil. Ciênc. Letr., Zoologia, 11, 5-254.

Meinken, H. (1925) Ein verkannter Laichräuber. Wochenschr. Aquarien u. Terrarienkunde, 22, 94-96.

Newmark, P.A., Wang, Y. \& Chong, T. (2008) Germ cell specification and regeneration in planarian. Cold Spring Harb. Symp. Quant. Biol., 73, 573-581. doi:10.1101/sqb.2008.73.022.

Ogukawa, K.I. (1955) On the supernumerary sexual organs of Dugesia gonocephala (Dugès), induced by low temperature. Bull. Kyoto Gakugei Univ., 6, 1-14.

Pala, M., Vacca, R.A., Casu, S. \& Stocchino, G.A. (1995) The freshwater planarian Dugesia sicula Lepori from Sardinia (Platyhelminthes, Tricladida). Hydrobiologia, 310, 151-156. doi:10.1007/ bfooo15533.

Pickavance, J.R. (1971) The diet of the immigrant planarian Dugesia tigrina (Girard). II. Food in the wild and comparison with some British species.J.Anim. Ecol., 40, 637-650. doi:10.2307/3442.

Puccinelli, I. \& Deri, P. (1991) Comparative karyological analysis of some American planarians belonging to the genus Dugesia (Subgenus Girardia) (Platyhelminthes, Tricladida). Caryologia, 44, 225-232. doi:10.1080/00087114.19 91.10797189.
Reynoldson, T.B. (1956) The occurrence in Britain of the American triclad Dugesia tigrina and the station of Dugesia gonocephala. Ann. Mag. Nat. Hist., 9, 102-105. doi:10.1080/002229356086 55731.

Reynoldson, T.B. (1985) An article on invasion. Take-over of an Anglesey lake by an American species of triclad - the potential threat to the native triclad fauna. Bull. Br. Ecol. Soc., 16, 80-86.

Ribas, M., Riutort, M. \& Baguña, J. (1989) Morphological and biochemical variation in populations of Dugesia (G.) tigrina (Turbellaria, Tricladida, Paludicola) from the western Mediterranean: biogeographical and taxonomical implications. J. Zool. (Lond.), 218, 6o9-626. doi:10.111//j.1469-7998.1989.tbo5003.x.

Sakurai, T. (1981) Sexual induction by feeding in an asexual strain of the freshwater planarian, Dugesia japonica japonica. Annot. Zool. Japon., 54, 103-112.

Sluys, R. (2001) Towards a phylogenetic classification and characterization of dugesiid genera (Platyhelminthes, Tricladida, Dugesiidae): A morphological perspective. In: D.T.J. Littlewood \& R.A. Bray (Eds) Interrelationships of the Platyhelminthes, Syst. Ass. Spec. Vol. ser. 6o, pp. 57-73. Taylor and Francis, London \& New York. Sluys, R. (2016) Invasion of the Flatworms. Am. Sci., 104, 288-295.

Sluys, R., Joffe, B. \& Cannon, L.R.G. (1995) An alien flatworm in Australian waters. Mem. Qld. Mus., 38, 642 .

Sluys, R., Kawakatsu, M. \& Ponce De León, R. (2005) Morphological stasis in an old and widespread group of species: Contribution to the taxonomy and biogeography of the genus Girardia (Platyhelminthes, Tricladida, Paludicola). Stud. Neotrop. Fauna Environ., 40, 155-180. doi:10.1080/01650520500070220.

Stagni, A. \& Grasso, M. (1965) Osservazioni preliminari sulla schizogenesi di Dugesia tigrina. Rend. Acc. Naz. Lincei, 38, 905-910.

Stella, E. \& Margaritora, F. (1966) Studio faunistico ed ecologico di un Lago-stagno del Lazio: Il Lago Monterosi. Arch. Zool. Ital., 51, 159-225. Downloaded from Brill.com04/26/2023 12:53:42PM via free access 
Stocchino, GA. (2018) 80 years of research on planarians (Platyhelminthes, Tricladida) from Sardinia, Italy: an annotated checklist. Zootaxa, 4532, 539-552. doi:10.11646/zootaxa.4532.4.5

Stocchino, G.A. \& Manconi, R. (2013) Overview of life cycles in model species of the genus Dugesia (Platyhelminthes, Tricladida). Ital. J. Zool., 8o, 319-328. doi:10.1080/11250003.2013.822025.

Stocchino, G.A., Sluys, R. \& Manconi, R. (2012) A new species of Dugesia (Platyhelminthes, Tricladida, Dugesiidae) from the Afromontane forest in South Africa, with an overview of freshwater planarians from the African continent. Zootaxa, 3551, 43-58.

Stocchino, G.A., Sluys, R. \& Manconi, R. (2014) A new and aberrant species of Dugesia (Platyhelminthes, Tricladida, Dugesiidae) from Madagascar. ZooKeys, 425, 71-88. doi:10.3897/ zookeys.425.7811.

Stocchino, G.A., Corso, G., Manconi, R. \& Pala, M. (2002) African planarians: Dugesia aethiopica sp. n. (Platyhelminthes, Tricladida) from Lake Tana (NW Ethiopia). Ital. J. Zool., 69, 45-51. doi:10.1080/11250000209356437.

Stocchino, G.A., Manconi, R., Cadeddu, B. \& Pala, M. (2013a) Freshwater triclads from Liguria. Boll. Mus. Ist. Biol. Univ. Genova, 75, 46-47.

Stocchino, G.A., Sluys, R., Deri, P. \& Manconi, R. (2013b) Integrative taxonomy of a new species of planarian from the Lake Ohrid basin, including an analysis of biogeographical patterns in freshwater triclads from the Ohrid region (Platyhelminthes, Tricladida, Dugesiidae). ZooKeys, 313, 25-43. doi:10.3897/zookeys.313.5363.

Stocchino, G.A., Sluys, R., Riutort, M., Solà, E. \& Manconi, R. (2017) Freshwater planarian diversity (Platyhelminthes, Tricladida, Duge- siidae) in Madagascar: new species, cryptic species, with a redefinition of character states. Zool. J. Linn. Soc., 181, 727-756. doi:10.1093/ zoolinnean/zlxo17.

Stocchino, G.A., Manconi, R., Corso, G., Sluys, R., Casu, S. \& Pala, M. (2009) African planarians: Morphology and karyology of Dugesia maghrebiana sp. n. (Platyhelminthes, Tricladida) from Tunisia. Ital. J. Zool., 76, 83-91. doi:10.1080/11250000802141683.

Tamura, S., Oki, I., Kawakatsu, M., Ninagawa, M., Matsusato, T. \& Suzuki, H. (1985) A note on an introduced species of freshwater planarian Dugesia tigrina (Girard, 1850) found in culture ponds of Australian crayfish in Kagoshima Prefecture, Japan. Bull. Fuji Women's Coll., No. 23, Ser. II, 133-137.

Vila, M., Sancho, M., Cardona, A., Fernández, J. \& Romero, R. (2004) Nueva población sexuada de Girardia tigrina (Girard, 1850) Kenk, 1974 (Platyhelminthes, Turbellaria, Tricladida, Dugesiidae), en el sur de Francia. Bol. R. Soc. Esp. Hist. Nat. Secc. Biol., 99, 49-53.

Vila-Farré, M., Sluys, R., Almagro, Í., HandbergThorsager, M. \& Romero, R. (2011) Freshwater planarians (Platyhelminthes, Tricladida) from the Iberian Peninsula and Greece: diversity and notes on ecology. Zootaxa, 2779, 1-38.

Wright, J.F. (1987) Colonization of rivers and canals in Great Britain by Dugesia tigrina (Girard) (Platyhelminthes: Tricladida). Freshwater Biol., 17, 69-78. doi:10.1111/j.1365-2427.1987.tbo1029.x.

RECEIVED: 29 NOVEMBER 2018 | REVISED AND

ACCEPTED: 25 APRIL 2019

EDITOR: R. VONK 